\title{
Molecular Diagnosis, Antimicrobial Resistance Profiles and Disease Patterns of Gram-Positive Pathogens Recovered from Clinical Infections in Major Ha'il Hospitals
}

\author{
Kamaleldin B. Said 1,2,3,*D(D, Ahmed Alsolami ${ }^{4}$, Amany M. Khalifa ${ }^{1}$, Nuha A. Khalil ${ }^{1}$, Soha Moursi ${ }^{1}$, \\ Ehab Rakha ${ }^{5,6}$, Abuzar Osman ${ }^{7}$, Musleh Rashidi ${ }^{8}$, Taha E. Taha ${ }^{9}$, Abdelhafiz I. Bashir ${ }^{10}$, Safia Moussa ${ }^{11}$, \\ Ahmed Al Jadani ${ }^{4}$, Hatem Nagi ${ }^{12}$, Mohammad Kuddus ${ }^{13}$, Obaid M. Alrashedi ${ }^{1}$, Amar S. Alharbi ${ }^{1}$, \\ Abdulrahman Alfaraj ${ }^{1}$, Roba Mustafa ${ }^{1}$ and on behalf of the Ha'il COM Research Unit Group ${ }^{+}$
}

check for updates

Citation: Said, K.B.; Alsolami, A.; Khalifa, A.M.; Khalil, N.A.; Moursi,

S.; Rakha, E.; Osman, A.; Rashidi, M.;

Taha, T.E.; Bashir, A.I.; et al.

Molecular Diagnosis, Antimicrobial Resistance Profiles and Disease Patterns of Gram-Positive Pathogens Recovered from Clinical Infections in Major Ha'il Hospitals. Microbiol. Res. 2022, 13, 49-63. https://doi.org/ $10.3390 /$ microbiolres13010004

Academic Editor: Beniamino T. Cenci-Goga

Received: 18 December 2021

Accepted: 18 January 2022

Published: 25 January 2022

Publisher's Note: MDPI stays neutral with regard to jurisdictional claims in published maps and institutional affiliations.

Copyright: (C) 2022 by the authors. Licensee MDPI, Basel, Switzerland. This article is an open access article distributed under the terms and conditions of the Creative Commons Attribution (CC BY) license (https:// creativecommons.org/licenses/by/ $4.0 /)$
1 Department of Pathology, College of Medicine, University of Ha'il, Ha'il 55476, Saudi Arabia; a.khalifa@uoh.edu.sa (A.M.K.); n.khalil@uoh.edu.sa (N.A.K.); Sohasma2011@gmail.com (S.M.); 201804279@uoh.edu.sa (O.M.A.); S201803978@uoh.edu.sa (A.S.A.); D7am1122@gmail.com (A.A.); rm.ahmed@liveuohedu.onmicrosoft.com (R.M.)

2 Genomics, Bioinformatics and Systems Biology, Carleton University, 1125 Colonel-By Drive, Ottawa, ON K1S 5B6, Canada

3 ASC Molecular Bacteriology, McGill University, 21111 Lakeshore Rd, Montreal, QC H9X 3L9, Canada

4 Department of Internal Medicine, College of Medicine, University of Ha'il, Ha'il 55476, Saudi Arabia; a.alsolami@uoh.edu.sa (A.A.); a.aljadani@uoh.edu.sa (A.A.J.)

5 Clinical Pathology Department, Faculty of Medicine, Mansoura University, Mansoura 35516, Egypt; ehabrakha@yahoo.com

6 Departments of Microbiology, King Khalid Hospital, Ha'il 55476, Saudi Arabia

7 Department of Pharmacology, College of Medicine, University of Ha'il, Ha'il 55476, Saudi Arabia; a.osman@uoh.edu.sa

8 Ministry of Health, Ha'il Region, Ha'il 55476, Saudi Arabia; Mreshidi@moh.gov.sa

9 Department of Epidemiology, John Hopkins Bloomberg School of Public Health, Baltimore, MD 21205, USA; ttaha1@jhu.edu

10 Department of Physiology, College of Medicine, University of Ha'il, Ha'il 55476, Saudi Arabia; ah.bashir@uoh.edu.sa

11 Department of Microbiology, King Salman Specialist Hospital, Ha'il 55476, Saudi Arabia; safiamoussa89@yahoo.com

12 Department of Community Medicine, College of Medicine, University of Ha'il, Ha'il 55476, Saudi Arabia; ha.adam@liveuohedu.onmicrosoft.com

13 Department of Biochemistry, College of Medicine, University of Ha'il, Ha'il 55476, Saudi Arabia; m.kuddus@uoh.edu.sa

* Correspondence: kbs.mohamed@uoh.edu.sa; Tel.: +966-500771459

$+\quad H a$ 'il College of Medicine (COM) Research Unit is a research-intensive hub that, in addition to housing advanced research initiatives, co-ordinates medical and clinical research in the college, and organizes, follows up, and facilitates Deanship Funded Research Programs such as annual "Research Groups" series, Badi, and other institutional local, national and regional program.

\begin{abstract}
Nosocomial resistance in staphylococci and enterococci is challenging. The aim of this work was to conduct a multipoint study using molecular detections, antimicrobial resistances profiles, patient demographics and disease patterns for objective assessments of Staphilococcus aureus and other Gram-positive pathogens recovered from clinical infections in the Ha'il region. We have surveyed 188 non-duplicate Gram-positives against 22 antimicrobials for molecular-differentiation, resistance, patient demographics, and disease patterns from January-April 2021. According to definitions for acquired resistance, Staphylococcus aureus was the most frequent with multidrug resistant $(65.4 \%)$, where MRSA was $60 \%$ ( $n=72$ out of 121$)$. In age-identified patients, $43 \%$ were seniors $\geq 50$ years, $38 \%$ 21-49 years, and 19\% 0-20 years. In gender-identified patients, $63 \%$ were males, and $37 \%$ were females. While $25 \%$ of specimens were from the ICU, the majority $(60 \%)$ of specimens were from surgical infection in other wards. Staphylococcus epidermidis was the second (15.4\%) species of infection identified with $81 \%$ from bloodstream infections at the ICU and other wards. The majority of $S$. epidermidis patients $(69 \%)$ were seniors $\geq 50$ years, while other age groups $0-20$ and $21-49$ each had $14 \%$ isolates. Although S. epidermidis was multidrug-resistant, it was susceptible to many
\end{abstract}


drugs. Enterococcus faecalis (13\%) ranked third with two major infections; bloodstream (64\%) and urinary-tract infections (36\%) in mainly seniors (86\%). Its isolates were fully resistant to oxacillin, penicillin, cefoxitin, and cefotaxime but nearly $100 \%$ susceptible to seven others. Other Gram-positive bacteria $(6 \%)$ were susceptible to many antibiotics. The use of combinations of objective criteria is a well thought out approach in infection control. While the low-frequency of Gram-positives is an impressive achievement, future large-scale investigations should include all private hospitals, clinics and other cities over a longer sampling time to gain more insights. Although geriatric susceptibility can be justified by age and comorbidities, the staphylococcal infections in young adults and children is a global concern and warrants more vertical studies.

Keywords: Gram-positive nosocomial resistance; MRSA; CA-MRSA; Staphylococcus aureus; resistance surveillance

\section{Introduction}

In recent years a significant increase in community associated infections and nosocomial antimicrobial resistances have occurred. Two primary examples are methicillinresistant Staphylococcus aureus (MRSA) and community-acquired (CA)-MRSA lineages. Unfortunately, extensive staphylococcal surveillance programs are limited or mostly outdated in the region. For instance, Abussaud M.J. [1], conducted a large multipoint surveillance study in a major Ha'il hospital, where out of 283 total bacterial isolates, 99 (35\%) belonged to S. aureus. Other surveillances of $S$. aureus resistance included nasal screening of 210 healthy participants from the eastern region of Saudi Arabia where a total of 63 S. aureus was found to colonize $37 \%$ of the community personnel and $26 \%$ total of the clinical students and healthcare workers (HCWs). The authors suggested simultaneous phenotypic and genotypic detections of $S$. aureus from healthy communities for potential transmissions [2]. The frequency of $S$. aureus resistance profiles in hospitals in recent decades is worrisome. A six-year (2013-2019) multicenter study on bloodstream infection rates in 246 intensive units of 83 hospitals in 14 countries in the Middle East revealed 55.2\% Gram-positive bacteria, with coagulase-negative staphylococci (31\%) and S. aureus (14\%) [3]. In addition, the recent emergences of novel as well as the previously unreported clonal complexes of MRSA strains in the regions is of concern [4-6]. Moreover, MRSA nasal colonization was reported in two nursing homes in Riyadh, Saudi Arabia where CA-MRSA (SCCmec IV and V) was more common than hospital-associated (HA) MRSA [7]. On the other hand, the zoonotic transmission of MRSA lineages is an emerging public health issue [8]. Furthermore, although MRSA pandemics have declined, methicillin-sensitive S. aureus (MSSA) bloodstreams infections are on the rise globally [9]. Thus, multiple factors, such as age, ICU, and comorbidities that influence the mortality and clinical outcomes for $S$. aureus bacteremia need to be taken into account. In addition, there remains many other predictors need to be addressed $[10,11]$. For example, as mentioned in the above reports, it is still elusive how new strains with enhanced virulence frequently emerge in hospitals and communities infecting even young otherwise healthy individuals with no risk factors [12]. For these reasons, multipoint surveillance along with patient demographics and disease patterns would be useful in proper assessments of $S$. aureus infections and resistance profiles in the Ha'il region.

Despite the pandemic emergences of invasive host- and organ-specialized lineages of S. aureus, little progress had been made on the development of rapid and suitable detection and typing methods. Fortunately, the introduction, in recent years, of automated multiplex molecular systems for rapid and specific point-of-care detection is being proved useful for the newly emerging and re-emerging subtypes in different hosts. These systems provide a unified approach in global efforts to trace the emergence and spread of MRSA lineages in different regions [13]. Specific detection and treatment lowers increased use, or abuse, of antibiotics, the biological cost of which on bacteria contribute to the evolution of more adapted 
lineages capable of global expansions. For instance, expansions of both USA300 lineage in Northern America, and the European ST80 in North Africa, Europe and the Middle East were attributed to low-level antibiotics exposure in human and animal environments [14]. In the latter regions, zoonotic and human to human transmissions can be uncontrollable and more serious than in Western countries and the USA where effective regulations are in place for the antibiotic use in agriculture and livestock productions. In addition to the biological cost, the USA300 lineage was found to have resistant staphylococcal protein A (SPA) modulation by the last resort antibiotic, linezolid, as well as by antipeptide [15]. For these reasons, continuous monitoring of $S$. aureus infections by surveillance programs using rapid automated molecular detection systems play important roles in confirming and guiding treatment options as well as preparing strains for vertical genetic studies and profiling for global control.

The data on nosocomial coagulase-negative staphylococci (CoNS) infections, such as S. epidermisis surveillance programs and reports on prevalence, are scarce in the region. Although there is evidence of its benefit [16], this organism is one of the most frequent causes of nosocomial sepsis posing significant medical and economic burdens that challenge advances in healthcare [17]. Earlier studies have established that episodes of CoNS nosocomial bacteremia were associated with significant mortality [18]. This has been true until recently where these genetically related organisms account for most cases of neonatal sepsis and morbidities including bronchopulmonary dysplasia, white matter injury, necrotizing enterocolitis, and retinopathy of prematurity $[19,20]$. Therefore, at present the role of S. epidermidis, particularly, in late-onset-sepsis has become a serious pathogenic problem as stated by Dong and Speer (2014) [21]. Vertical molecular studies have provided more insights into CoNS infections and the routes of their acquisitions. The next generation sequencing (NGS) and quantitative-PCR (qPCR) microarray analyses confirmed the impact of the hospital environment microbiome on S. aureus and S. epidermidis nasal colonization rates [22]. Moreover, studies on isolates from 96 institutions in 24 countries identified the global emergence of multidrug-resistant, hospital-adapted lineages of S. epidermidis (two ST2 and one ST23). These lineages have a unique rifampicin resistance that also reduces susceptibility to the last-line glycopeptide antibiotics, vancomycin and teicoplanin [23]. Thus, S. epidermidis, is emerging in different regions posing as a potential pandemic. Surveillance of S. epidermidis for phenotypic and genotypic antimicrobial strain profiles has become imperative for efficient control of nosocomial infections especially in pediatric hospitals and units.

Since the first definition of the acronym ESKAPE by [24] Rice (2008), which stands for pathogens Enterococcus, Staphylococcus aureus, Klebsiella pneumoniae, Acinetobacter baumannii, Pseudomonas aeruginosa and Enterobacter species, resistant enterococcus remained first in the list [25]. There have been increasing reports on resistant Enterococcus spp. in many countries including France, Poland, Iran, China, and USA [26-29]. In the latter study, a five-year USA hospital cohort study examined 41.6 million hospitalizations for multidrug resistances that caused 622,390 infections in 2017 alone, where $83 \%$ were community acquired [27]. In the aforementioned study, while the incidence of MRSA and vancomycin resistant enterococcus (VRE) slightly decreased, that of carbapenem-resistant Enterobacteriaceae infection remained unchanged. Similarly, a PubMed and EMBASE databases search for VRE colonization of the gastrointestinal tract in pediatric hospitals returned 20,234 hits where colonized children were almost nine times more likely to develop subsequent VRE infection in USA [30]. More important is that the treatment alternatives for Enterococcus faecalis infective endocarditis (IE) in the outpatient setting is challenging. Three database-searches by species and best treatment regimen returned 18 studies where aminoglycosides and dual $\beta$-lactam alternatives showed evidence of efficacy. The latter alternative being suitable for aminoglycoside resistance and for reduced toxicity [31]. However, the increasing rates of coinfection with severe COVID-19 after hospital admission is a new scenario that aggravates the disease. These include Gram-positive species such as MRSA and vancomycin-resistant enterococci [20]. Surveillance programs for detection and estimation of enterococcus 
species in the regions need to be updated and intensified. The first incidence of vanB phenotype-vanA genotype incongruence in the Middle East was reported by Al-Ahdal et al. (2012) [32]. Consequently, evolving VRE epidemiology with vanA(+)/vanB(+) isolates and vanA genotype-vanB phenotype have become major clinical isolates in the region, which were described as colonizers [33]. Since then, increasing trends in severity and clinical outcomes of enterococci have been reported in Saudi Arabia [34]. Similar surveillance programs and regular resistance profiling is needed in the region to direct appropriate treatment decisions. The aim of this study was to carry out a multipoint study using molecular detections, antimicrobial resistances profiles, patient demographics and disease patterns for objective assessments of $S$. aureus and other Gram-positive pathogens in clinical infections in the Ha'il region.

\section{Materials and Methods}

\subsection{Ha'il Province and All Its Socioeconomic Strata}

The Ha'il population is nearly one million. Ha'il city lies in north-central Saudi Arabia and has two tertiary care centers namely, King Salman Specialist Hospital and King Khalid Hospital, and two major hospitals Ha'il General Hospital (245 beds) and Maternity and Children Hospital (300 beds). These public hospitals serve Ha'il City and all socioeconomic strata of the province.

\subsection{Study Designs, Data Sources, and Statistical Analysis}

This study investigated positive cultures of major Gram-positive non-duplicate isolates collected from four major cohort Ha'il hospitals between January and April 2021. This work is an objective multipoint study that considers a multifactorial approach in understanding all aspects of Gram-positive bacterial infections while evaluating MRSA screening protocol in place. It uses molecular diagnostics, antimicrobial resistances profiles, patient demographics, and disease patterns for objective assessments of $S$. aureus and other Gram-positive pathogens recovered from clinical infections in the Ha'il region. Data were obtained from microbiology laboratory records, hospital medical records, various sources within hospitals, but rarely from COVID-19 isolation zones because the latter is held in a specialized hospital. The data included but were not limited to resistance profiles, SARS-CoV-2 bacterial coinfection, specimen types and collection sites, admitting ward, and age and gender differences from four participating hospitals. To determine community acquired infections, data taken within $48 \mathrm{~h}$ of admission were used for analysis.

\subsection{GeneXpert Molecular Detection Systems}

Multi-gene molecular kits were used for robust automated detection of S. aureus specimens (as shown in Table 1 in text and Table S1 in Supplementary Materials) in addition to cefoxitin screening using GeneXpert-RT-PCR for S. aureus and MRSA multikits systems. MRSA was confirmed by agar diffusions. Collected data were analyzed using Statistical Package for Social Sciences software (SPSS; Version 23 SPSS version 23.0 for Windows (SPSS, Inc., Chicago, IL, USA) (statistical analysis files for the species are included in the Supplementary Materials Tables S2-S4). Pathogens were identified by using routine standard bacteriological methods and ID and susceptibility testing using automated systems. This included primarily GeneXpert systems for molecular diagnostics and strain and species confirmations. In addition, Vitek2 system (bioMérieux, MarcylE'toile, France), BD Phoenix system (BD Biosciences, Franklin Lakes, NJ, USA), MicroScan plus (Beckman Coulter, Brea, CA, USA), and BD BACTEC system (BD Biosciences) for the identification and antimicrobial sensitivity analysis of microorganisms were used. These systems are used in different hospitals; however, all isolates were screened by BD Phoenix combined identification, antimicrobial testing, and florescence control at King Khalid Hospital. Routine bacteriology work was applied for confirmation and vertical analysis. Susceptibility was confirmed by culture and agar diffusions experiments. The susceptibility testing and breakpoint interpretive standards were carried out in accordance with the 
recommendations of the Clinical and Laboratory Standard Institute (CLSI document M100S26) [35].

Table 1. Specimen types, sources, patient demographics, and antimicrobial resistance definitions of major Gram-positive bacteria recovered from clinical isolates in Ha'il hospitals, Saudi Arabia.

\begin{tabular}{|c|c|c|c|c|c|c|c|c|}
\hline \multirow{3}{*}{ Ward $^{\text {a }}$} & \multicolumn{8}{|c|}{ Total Clinical Isolates of Gram-Positive Bacteria $(n=188)$} \\
\hline & \multicolumn{2}{|c|}{ S. aureus $(65.4 \%, n=123)$} & \multicolumn{2}{|c|}{ S. epidermidis $(15.4 \%, n=29)$} & \multicolumn{2}{|c|}{ E. faecalis $(13 \%, n=25)$} & \multicolumn{2}{|c|}{$\begin{array}{l}\text { Other-Gram-Positive } \\
\text { Bacteria }(6 \%, n=11)\end{array}$} \\
\hline & $n$ & $\%$ & $n$ & $\%$ & $n$ & $\%$ & $n$ & $\%$ \\
\hline $\begin{array}{l}\text { Intensive Care Unit } \\
\text { ICU }\end{array}$ & $\begin{array}{c}28 \\
\text { Blood, } \\
\text { respiratory soft } \\
\text { tissue infections } \\
\text { (12) Wound/pus } \\
\text { AE (16) }\end{array}$ & 25 & $\begin{array}{c}11 \\
\text { Blood (11) }\end{array}$ & 38 & $\begin{array}{c}10 \\
\text { Blood (8) } \\
\text { Urine (2) }\end{array}$ & 40 & $\begin{array}{c}1 \\
\text { Urine }\end{array}$ & 9 \\
\hline $\begin{array}{c}\text { COVID-19 } \\
\text { Isolation Zones } \\
\text { (ISO) OR COVID } \\
\text { Ward (COW) }\end{array}$ & 1 & 1 & 0 & 0 & 1 & 4 & 0 & 0 \\
\hline $\begin{array}{l}\text { Surgical infections } \\
\text { FMW, FSW, MMW, } \\
\text { MSW, and AKU }\end{array}$ & $\begin{array}{c}67 \\
\text { Pus (7), Wounds, } \\
\text { skins, swabs, etc. } \\
\text { (36) Throat and } \\
\text { nasal collections } \\
\text { (14) }\end{array}$ & 60 & $\begin{array}{c}8 \\
\text { Blood (8) }\end{array}$ & 27.6 & $\begin{array}{c}11 \\
\text { Blood (4) } \\
\text { Urine (6) } \\
\text { Wound (1) }\end{array}$ & 44 & $\begin{array}{c}9 \\
\text { Urine (2) } \\
\text { Blood (4 } \\
\text { Wound (3) }\end{array}$ & 82 \\
\hline Other & 27 & 14 & $\begin{array}{l}10 \text { (swabs (2), pus } \\
\text { (1), vitreous (1), } \\
\text { peritoneal fluid (1) } \\
\text { Av necrosis (1), lab } \\
\text { origin (2) }\end{array}$ & 34.5 & 3 & 12 & 1 & 9 \\
\hline $\begin{array}{l}\text { Total } \\
\text { Age }\end{array}$ & 123 & $100 \%$ & 29 & $100 \%$ & 25 & $100 \%$ & 11 & $100 \%$ \\
\hline Young 0-20 & 21 & 19 & 4 & 14 & 1 & 4 & 0 & 0 \\
\hline Adults (21-49 yrs.) & 41 & 38 & 4 & 14 & 2 & 8 & 0 & 0 \\
\hline Seniors ( $>50$ yrs.) & 46 & 43 & 20 & 69 & 19 & 76 & 9 & 82 \\
\hline $\begin{array}{l}\text { Age unidentified } \\
\text { Gender }\end{array}$ & 15 & 12 & 1 & 3.4 & 3 & 12 & 2 & 18 \\
\hline Male & 70 & 63 & 16 & 55 & 16 & 64 & 3 & 27 \\
\hline Female & 41 & 37 & 13 & 45 & 9 & 36 & 8 & 73 \\
\hline $\begin{array}{c}\text { Gender } \\
\text { unidentified }\end{array}$ & 12 & 10 & 0 & 0 & 0 & 0 & 0 & 0 \\
\hline MDR, XDR, PDR ${ }^{b}$ & $\begin{array}{l}\text { MItisfies both opt } \\
\text { by virtue of } \\
\text { non-susceptible } t \\
\text { antimicrobi }\end{array}$ & $\begin{array}{l}\text { r MDR: (i) } \\
\text { is (ii) } \\
\text { gent in } \geq 3 \\
\text { ories }\end{array}$ & MDR & & & & & \\
\hline
\end{tabular}

${ }^{a}$ Ward = Female and male medical and surgical, emergency wards, and Alkaptonuria male rooms (FMW, FSW, MMW, MSW, AKU). ${ }^{\mathrm{b}}$ multi drug-resistant, extensive drug-resistant and pan drug-resistant.

\subsection{Classifications as Multi-, Extremely-and Pan-Drug Resistant Bacteria (MDR, XDR, and PDR)}

Based on standard definitions for acquired resistance, microorganisms were classified as multi drug-resistant (MDR), extensive drug-resistant (XDR), and pan drug-resistant (PDR) according to the guidelines of the European Centre for Disease Control. MDR was defined as acquired non-susceptibility to at least one agent in three or more antimicrobial categories, XDR was defined as non-susceptibility to at least one agent in all but two or fewer antimicrobial categories (i.e., bacterial isolates remain susceptible to only one or two categories) and PDR was defined as non-susceptibility to all agents in all antimicrobial categories as reported by Magiorakos et al. (2012) [36]. Intrinsic resistances to particular drugs were not included.

Criteria for defining MDR, XDR, and PDR in S. aureus MDR (one or more of the following have to apply):

(i) An MRSA is always considered MDR by virtue of being an MRSA.

(ii) Non-susceptible to $\geq 1$ agent in $\geq 3$ antimicrobial categories.

(iii) XDR: non-susceptible to $\geq 1$ agent in all but $\geq 2$ categories.

(iv) PDR: non-susceptible to all antimicrobial agents listed. Oxacillin or cefoxitin represents all other b-lactams (and cephamycins) and resistance to either of these predicts non-susceptibility to all categories of b-lactam antimicrobials listed in this document, 
with the exception of the anti MRSA cephalosporins (i.e., all categories of penicillin, cephalosporins, b-lactamase inhibitors and carbapenems currently approved).

Available online: http://www.ecdc.europa.eu/en/activities/diseaseprogrammes/ ARHAI/Pages/public_consultation_clinical_microbiology_infection_article.aspx (accessed on 1 January 2022).

\subsection{Molecular Detection of Spa Gene, mecA, and mec (SCCmec)}

The Cepheid Xpert SA Nasal Complete assay was used in the detection of $\operatorname{spa}, \operatorname{mec} A$, and the mec (SCCmec) gene sequences from specimens. The Cepheid ${ }^{\circledR}$ Xpert SA Nasal Complete assay performed in the GeneXpert ${ }^{\circledR}$ Dx System was used in vitro rapid detection of S. aureus (SA) and MRSA from nasal swabs of patients following manufacturers recommendations. This test utilizes an automated real-time polymerase chain reaction (PCR). Concomitant culturing was carried out from all suspected specimens for further susceptibility testing. The GeneXpert Dx is an all-in-one system that integrates sample purification, nucleic acid amplification, and detection of the target sequence in simple or complex samples using real-time PCR and RT-PCR assays. The system consists of an instrument, personal computer, and preloaded software for running tests and viewing the results. The system requires the use of single-use disposable cartridges that hold the PCR reagents and host the PCR process. Because the cartridges are self-contained, cross-contamination between samples is minimized. A sample processing control (SPC) and a probe check control (PCC) are also included. The SPC is present to control for adequate processing of the target bacteria and to monitor the presence of inhibitor(s) in the PCR reaction. The PCC verifies reagent rehydration, PCR tube filling in the cartridge, probe integrity, and dye stability. Identification by GeneXpert ${ }^{\circledR}$ vanA/vanB PCR and ChromID VRE routinely screen rectal samples for VRE colonization among critically ill patients. All isolates in this study, except one, were sensitive for vancomycin on primary automated analysis by phoenix. For that they were not tested further by GeneXpert ${ }^{\circledR}$.

\section{Results}

\subsection{Staphylococcus aureus}

Staphylococcus aureus was the most frequent among the overall 188 Gram-positive pathogens $(n=123,65.4 \%)$ isolated from clinical specimens as shown in Table 1. Of the age identified patients $(n=108), 43 \%(n=46)$ were seniors with underlying risk factors for hospitalization, $19 \%(n=21)$ were patients from 0 to 20 years of age, and $38 \%(n=41)$ were young adults and mid-aged 21 to 49 years of age. In gender differences, $63 \%$ were male patients $(n=70)$, while $37 \%$ were females $(n=41)$ of the gender identified patients $(n=111)$. Of the $S$. aureus positive specimens per specific wards (111 specimens; while 12 were shared between wards/units or hospitals), $25 \%(n=28)$ were from intensive care units (ICU); of which $43 \%(n=12)$ were from seniors with blood and respiratory infections while the remaining majority were wound infections in children and mid-age patients below 50 years ( 0 to 49 years old). However, the majority, $60 \%$ of specimens $(n=67)$, were largely from surgical infection, male and female medical, pediatric, and emergency wards. The rest of the specimens came from various wards including a single case of coinfection with SARS-CoV-2. Antibiogram of S. aureus (Figure 1) showed susceptibility to 14 antibiotics ranging from $73.9 \%$ to $100 \%$ of isolates. These included linezolid (LNZ $100 \%$ ), nitrofuran (NIT 100\%), rifampicin (RD 98\%), teicoplanin (TEC 98\%), mupirocin (MUP 98.3\%), vancomycin (VA 97.5\%), moxifloxacin (MXF 97.5\%), clindamycin (CD 93.5\%), daptomycin (DAP 92\%), tetracycline (TE 85.9\%), trimethoprim/sulfamethoxazole (SXT $79.5 \%)$, gentamicin (CN7 8.8\%), ciprofloxacin (CIP 76\%), and ertapenem (E 73.9\%). The rest of the antibiotics showed higher resistances ranging from $58 \%$ to almost $100 \%$ of isolates showing resistances including; IMI 58.5\%, CTX 60.6\%, FOX 61\%, AMS 62\%, OX 62.6\%, AMP $95 \%$, and P $97.7 \%$. Importantly, the pattern of antibiogram indicated that of CA-MRSA, where most resistances were in beta lactam and cephalosporins categories of antimicrobials, 
while isolates were largely susceptible to non-beta lactams (Figure 1). Based on Magiorakos et al. (2012), MRSA is always considered MDR by virtue of being an MRSA.

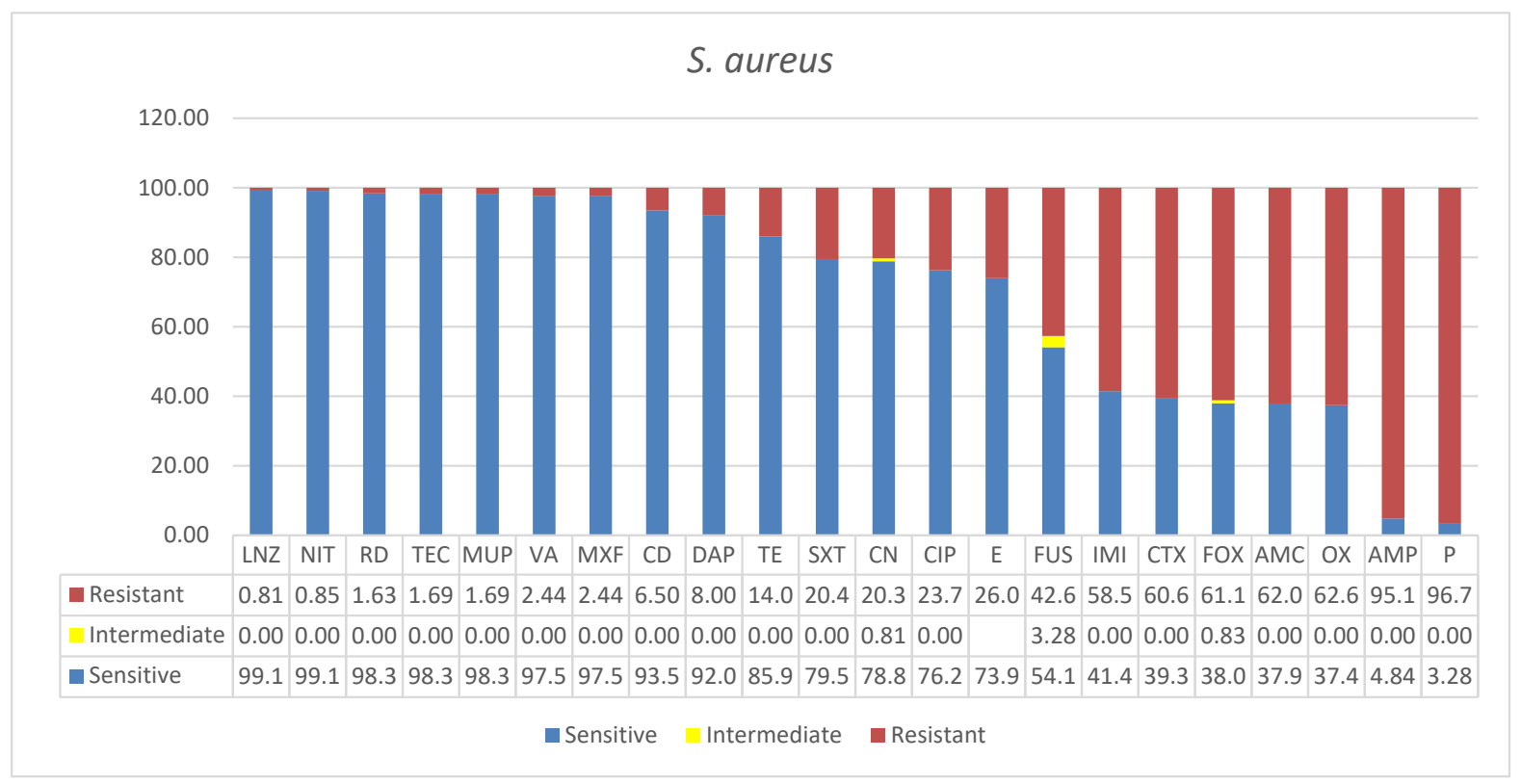

Figure 1. Antimicrobial sensitivity patterns of $S$. aureus isolates to 22 antibiotics. Abbreviations (in the order in which they appear in the figure): LNZ linezolid, NIT nitrofuran, RD rifampicin, TEC teicoplanin, MUP mupirocin, VA vancomycin, MXF moxifloxacin, CD clindamycin, DAP daptomycin, TE tetracycline, SXT trimethoprim*/sulfamethoxazole, CN gentamicin, CIP ciprofloxacin, ERY erythromycin, FUS fusidic acid, IMI imipenem, cefotaxime CTX, cefoxitin FOX, AMC AMPICILLIN*/SULBACTAM, OX oxacillin, AMP ampicillin, P penicillin.

\subsection{Staphylococcus epidermidis}

Staphylococcus epidermidis was identified in 29 clinical specimens that made up 15.4\% of overall 188 Gram-positive species isolated in this study from different sources as shown in Table 1 . The $81 \%$ (of 26 sources specified specimens) were from blood infections $(n=21)$ the majority of which $(52.4 \%)$ were in the ICU $(n=11)$ and $38 \%(n=8)$ were from surgical infections in male, female, medical and surgical wards and alkaptonuria rooms (Table 1 ). The majority of patients $(69 \%, n=20)$ were seniors over 50 years of age where males were $55 \%(n=16)$ and females were $45 \%(n=13)$. Age groups 0 to 20 and 21 to 49 each had $14 \%(n=4)$ of isolates. The antibiogram (Figure 2$)$ showed that for four antibiotics, DAP, VA, NIT, and TE, full susceptibility for $100 \%$ of isolates was seen. The rest of the drugs ranged from highly susceptible to resistant; the following showed high susceptibility LNZ 93\%, TEC 92.6, MUP 82.8\%, MXF 82.8\%, CN 75.9\%, IMI 72.4\%, CTX 72.4\%, AMS 72.4\%, CD 72.4\%, FOX 67.9\%, SXT 67.9\%, while the following showed higher resistances, CIP $51.7 \%$, OX 62\%, AMP 81.5\%, P 81.5\%, and E 86.2\%. For the antibiotic FUS, $86.2 \%$ of isolates showed a unique intermediate response.

\subsection{Enterococcus faecalis}

Twenty-five $(n=25)$ clinical specimens were positive for E. faecalis isolates in this study (Table 1$)$. The overwhelming majority of the age of identified patients $(n=22)$ were seniors at higher extremes of life and residents of long-term care facilities $(n=19,86 \%)$. Overall, two major types of infections were common; blood infections (64\%) and urinary tract infections (UTIs) (36\%) both types were collected at the ICU, medical, and ER wards (Table 1). The antibiogram of E. faecalis showed that for over half of the drugs, isolates were resistant, reaching 100\% resistance in four drugs, namely, oxacillin (OX 100\%), penicillin G (P 100\%), cefoxitin (FOX 100\%), and cefotaxime (CTX 100\%). However, for nine antibiotics, 
over $80 \%$ of isolates were susceptible, seven of which had over $92 \%$ susceptibility including vancomycin (VA 96\%), teicoplanin (TEC 96\%), linezolid (LNZ 96\%), ampicillin (AMP 92\%), ampicillin/sulbactam (2/1) (AMS 92\%), daptomycin (DAP 92\%), nitrofuran (NIT 88\%), and imipenem (IMI 80\%) (Figure 3).

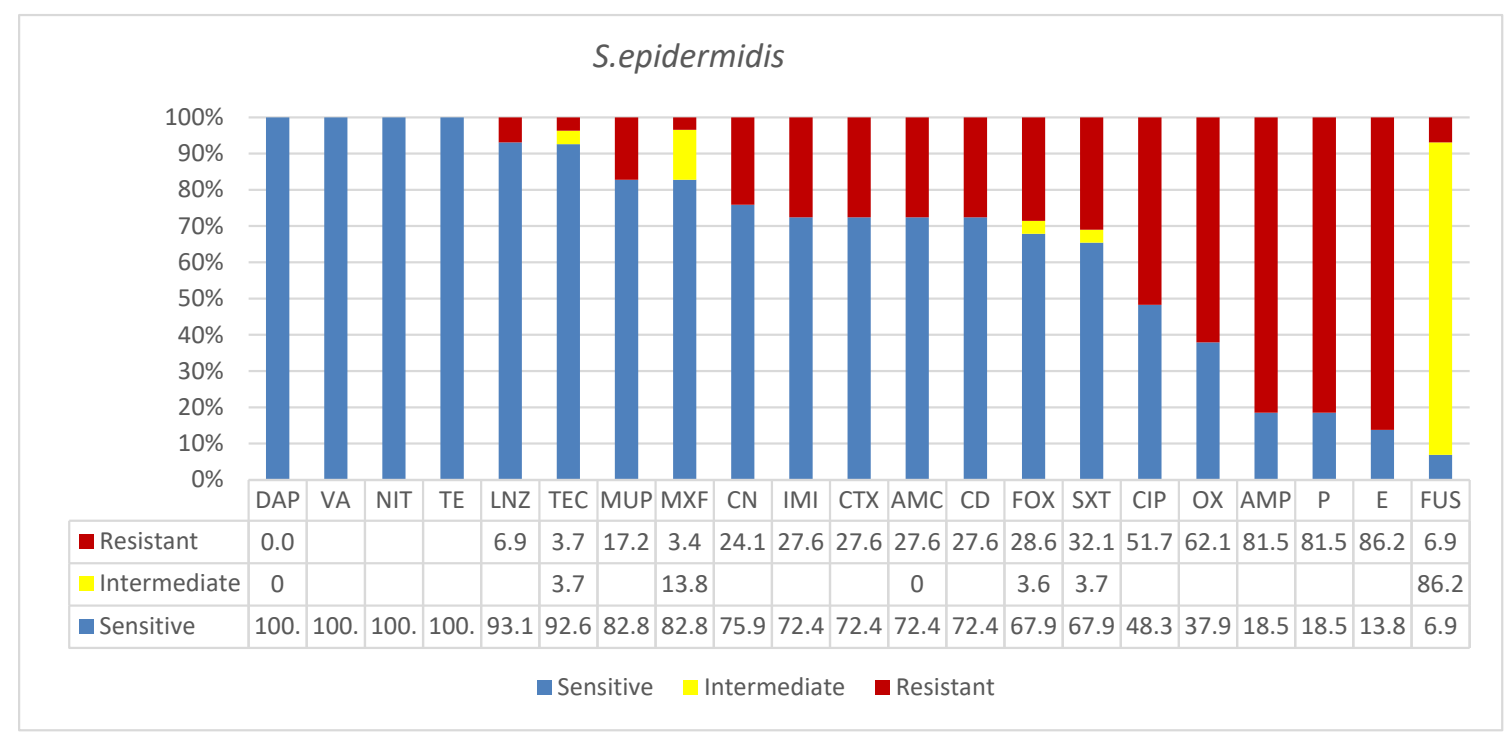

Figure 2. Antimicrobial sensitivity patterns of S. epidermidis isolates to 21 antibiotics. Abbreviations (in the order in which they appear in the figure): DAP daptomycin, VA vancomycin, NIT nitrofuran, TE tetracycline, LNZ linezolid, TEC teicoplanin, MUP mupirocin, MXF moxifloxacin, CN gentamicin, IMI imipenem, CTX cefotaxime, AMC ampicillin/sulbactam, CD clindamycin, FOX cefoxitin, SXT trimethoprim/sulfamethoxazole, CIP ciprofloxacin, OX oxacillin, AMP ampicillin, P penicillin, E erythromycin, FUS fusidic acid.

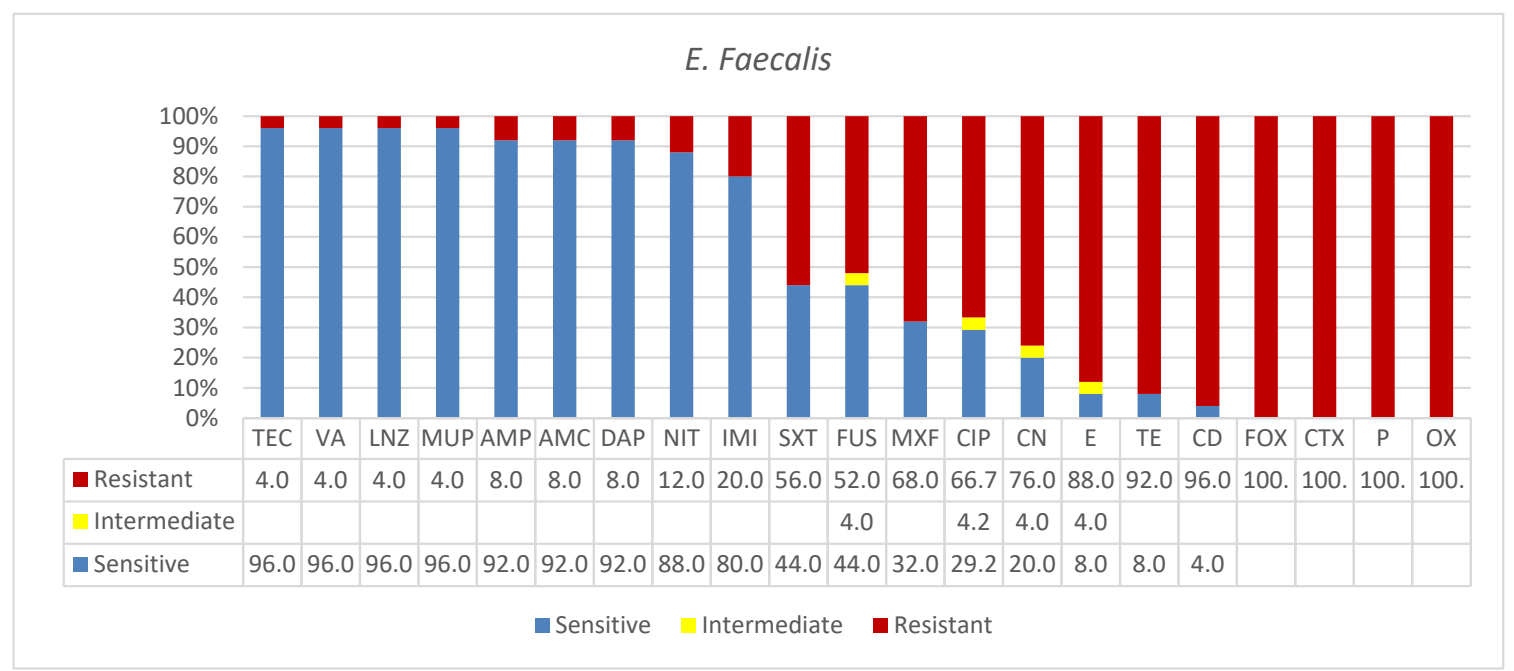

Figure 3. Antimicrobial sensitivity patterns of E. faecalis isolates to 21 antibiotics. Abbreviations (in the order in which they appear in the figure): TEC teicoplanin, VA vancomycin, LNZ linezolid, MUP mupirocin, AMP ampicillin, AMC ampicillin/sulbactam, DAP daptomycin, NIT nitrofuran, IMI imipenem, SXT trimethoprim/sulfamethoxazole, FUS fusidic acid, MXF moxifloxacin, CIP ciprofloxacin, CN gentamicin, E erythromycin, TE tetracycline, CD clindamycin, FOX cefoxitin, CTX cefotaxime, $\mathrm{P}$ penicillin, OX oxacillin. 


\subsection{Other Gram-Positive Bacteria}

Eleven "Other Gram-positive bacteria" (Table 1) were isolated from clinical specimens of various sources. Most of the above $(82 \%, n=9)$ were isolated from blood, urine, and wound infections in surgical female and male medical wards and from the alkaptonuria male rooms. Only one case was reported from the ICU. For the age identified patients, no isolations were reported from patients 0 to 49 years old and only two patients were age unidentified. However, all reported patients $(82 \%, n=9)$ were seniors over 50 years the majority of which were male $(73 \%, n=8)$ and only three were females. Among these species, six E. faecium isolates showed the following pattern of susceptibility; they were fully resistant to the following antibiotics, except for one sensitive isolate in each, clindamycin $\mathrm{CD}$, erythromycin E, and tetracycline TE. Fifty percent were resistant to NIT, and MXF, while $67 \%$ were resistant to fusidic acid FUS and ciprofloxacin CIP. Isolates for the rest of the antibiotics showed high susceptibilities. In this group of "Other Gram-positive bacteria", S. acidominimus was the only vancomycin resistant species. These pediatric blood isolates also tested sensitive against telithromycin, pristinamycin, and levofloxacin but were resistant to chloramphenicol. All four S. agalactiate isolates from the maternity hospital responded well to selected antimicrobials.

\section{Discussion}

In this study, we have surveyed antimicrobial resistance profiles of Gram-positive nosocomial and potentially community acquired pathogens isolated from clinical specimens at major hospitals in Ha'il City Saudi Arabia. Furthermore, we studied the influence of the specimens' sources and basic patients' demographics in their susceptibility to infections. As shown in Table 1 , S. aureus was positive in 123 clinical specimens, the majority of which caused surgical infections involving mainly blood and soft tissue. Increasing frequencies of infections with age was observed where senior patients over 50 years had the most $(43 \%)$ infections followed by age groups 21 to $49(38 \%)$ and 0 to $20(19 \%)$. It has been well documented that some portions of the latter age-groups of patients can be vulnerable to different types of $S$. aureus lineages even without any underlying causes [2,12]. Plausible explanations are their increased activities and social gathering facilitate transmissions, the acquisition of resistance may aid in fitness, and differences in related host factors. However, these are not fully understood and each one alone does not explain the magnitude of the virulence per se. A few studies demonstrated variations in nasal bacteriome components as a risk factor. For instance, interference with $S$. aureus colonization was shown by lugdunin producing Staphylococcus lugdunensis [37]. However, the increased infection $(60 \%$, and $25 \%$ ) in the ICU, surgical wards, male and female medical, pediatric, and emergency wards is consistent with earlier reports [3]. Despite the progress made in previous decades of declining MRSA infections, soft tissue and bloodstream infections by Gram-positive species, particularly, Staph.aureus strains, are still a significant burden globally [2,3,9]. Another pattern of infection in the present study is the gender differences in susceptibility to Staph. aureus infections. Increased frequency of infections in men compared to women was observed where $63 \%$ of the former patients compared to $37 \%$ of latter were infected with this species. This potentially implied that being a senior and a male are risk factors for S. aureus bloodstream infections similar to findings by Bandy et al., [38]. In recent reports, we and others in Saudi Arabia, as well as from other countries, have shown these observations in Gram-negative bacteria [38-40]; similarly, here we show a similar pattern in Gram-positive bacterial infections, particularly, S. aureus. These findings have significant implications for geriatric patient management strategies and treatment protocols. The use of FOX and GeneXpert proved useful in rapid detection, and differentiations followed by confirmation by agar diffusions, where $60 \%$ ( $n=72$ of $121 \mathrm{~S}$. aureus, two isolates were variable) were MRSA. The finding of two isolates as methicillin sensitive by FOX despite having the mecA gene present by GeneXpert PCR warrants further investigation into the expression profiles at the gene locus. In addition, the significant increase in MSSA infections $(40 \%)$ is consistent with the recent trend in different countries [9]. 
Twenty-nine clinical specimens were positive for S. epidermidis. Most of the isolates were from blood infections ( $81 \%$ ) at the ICU, medical, and surgical wards. This is consistent with the various reports on frequent S. epidermidis nosocomial sepsis that has become one of the healthcare challenges $[17,18]$. While a few cases $(n=4)$ occurred in adults and children, bloodstream infections by the multidrug resistant $S$. epidermidis were confined to elder patients almost equally in males and females in this study. Although our samples were smaller, the study alerted to the rising rates of $S$. epidermidis bloodstream infections Although mutations in the rpoB in S. epidermidis ST2 and ST23 were reported to reduce susceptibility to the last-line glycopeptide antibiotics, vancomycin and teicoplanin [23], S. epidermidis isolated in this study were susceptible to the latter antibiotics $(100 \%$ and $93 \%$, respectively). Furthermore, the recent frequent clonal emergences of LNZ-resistant lineages in many countries including France, Germany, Ireland, Poland, Australia, and other regional countries such as Iran, are worrisome [41,42]. In the present study, $7 \%$ of isolates were resistant to LNZ; further genome-sequence based studies and genotyping of these isolates and all others is important. In addition, high levels of penicillin and cefoxitin (indicative of methicillin resistance) in S. epidermidis were found in this study in agreement with reports on the global spread in several countries including China and the UK [43,44]. Thus, these findings disprove conventional notions in S. epidermidis management strategy in hospitals that isolation from blood cultures is always a contamination or indolent compared with other bacteria. Future molecular studies and genome-based antimicrobial surveillance would gain more insights into the emerging resistant clones in the regions [45]. E. faecalis was isolated from 25 clinical specimens $(13 \%)$ of the total $(n=188)$ bacterial species in this study, where $64 \%$ of which were blood infections and $36 \%$ were UTIs. Considering the differences in city populations, this is much higher than the $3 \%$ isolated from a major tertiary hospital in Riyadh, Saudi Arabia between 2015 and 2016 [46]. The overwhelming majority of patients were seniors in long term care facilities $(82 \%)$ and male $(46 \%)$. Similar studies on this specific finding in the region for comparison are rare. A recent uropathogenic study in China revealed a similar pattern where E. faecalis showed a higher frequency in males $(15.6 \%)$ than in females $(2.9 \%, p<0.001)$ [45]. E. faecalis was resistant to over half of the antibiotics tested; particularly, for beta-lactams and cephalosporins where nearly $100 \%$ of isolates were resistant, except for ampicillins. However, for non-beta lactam antibiotics, they were relatively susceptible, but for seven antibiotics including vancomycin (VA $96 \%$ ), over $92 \%$ of isolates were highly susceptible (Figure 3). This pattern is consistent with that of the global profile of enterococcus resistance in many countries [25-29,47]. Introduction of genome-based surveillance and molecular analysis has been successful in infection control practices in Saudi Arabia. A recent genomic analysis and sequence typing of multidrug-resistant clinical Enterococcus faecalis isolates in the western region of the country revealed 17 MDR sequence types including two novel STs (ST862 and ST863 [47]). However, in microbiology routine practice, distinction between community acquired and hospital strains is not always clear. In a recent large-scale study, most infections were found to originate in the community as determined by a five-year USA hospital cohort examining 41.6 million hospitalizations where $83 \%$ were community acquired [27]. Fortunately, VRE is rare in all hospitals screened in this study, where only a single VRE isolate (4\%) was reported. This isolate was recovered from a urine sample of an 80-year-old male at an ER department. It was susceptible only to imipenem and resistant to others including ampicillin that potentially ruled out the pattern of Penicillin-Resistant, Ampicillin-Susceptible Enterococcus faecalis (PRASEF) clone phenotype. Unfortunately, the intrinsic resistance to cephalosporins, and the increasing resistance to $\beta$-lactams are limiting their use in combination with aminoglycosides or for predictions of imipenem susceptibility by ampicillin testing. However, in contrast to other species, E. faecalis remained usually susceptible to the other $\beta$-lactam antibiotics, including the carbapenems. Although the surrogate predictions could further confirm susceptibility, the low prevalence rates of PRASEF occasionally limit its evaluation as a marker [47,48]. Future surveillance and vertical studies will reveal more insights into the emerging phenotypes in isolates from 
different age groups. For instance, gastroenteritis, particularly in pediatrics, is likely to predispose to serious VRE infections [20], leading to subsequent infective endocarditis and potential coinfection with COVID-19 aggravating the disease. Although VRE was first reported in the Middle East by Al-Ahdal et al. (2012) [32], the incidence rates have remained low in the Ha'il region, mostly due to its geographic location in the northern region which is remote from populated cities, as well as the stricter antimicrobial usage program.

Eleven isolates belonging to "Other Gram-positive bacteria" was included in a separate category because they were low in numbers and are comparatively rare (Figure 4). Among these, six E. facium isolates were fully resistant to lindamycin $C D$, erythromycin $E$, and tetracycline TE, 50\% were resistant to NIT and MXF, and 67\% were resistant to fusidic acid FUS and ciprofloxacin CIP. However, for the rest of the antibiotics more isolates were susceptible. In this group, S. acidominimus was the only vancomycin resistant species. These pediatric blood isolates also tested sensitive against telithromycin, pristinamycin, and levofloxacin but were resistant to chloramphenicol. All four S. agalactiate isolates from the maternity hospital were susceptible to selected antimicrobials.

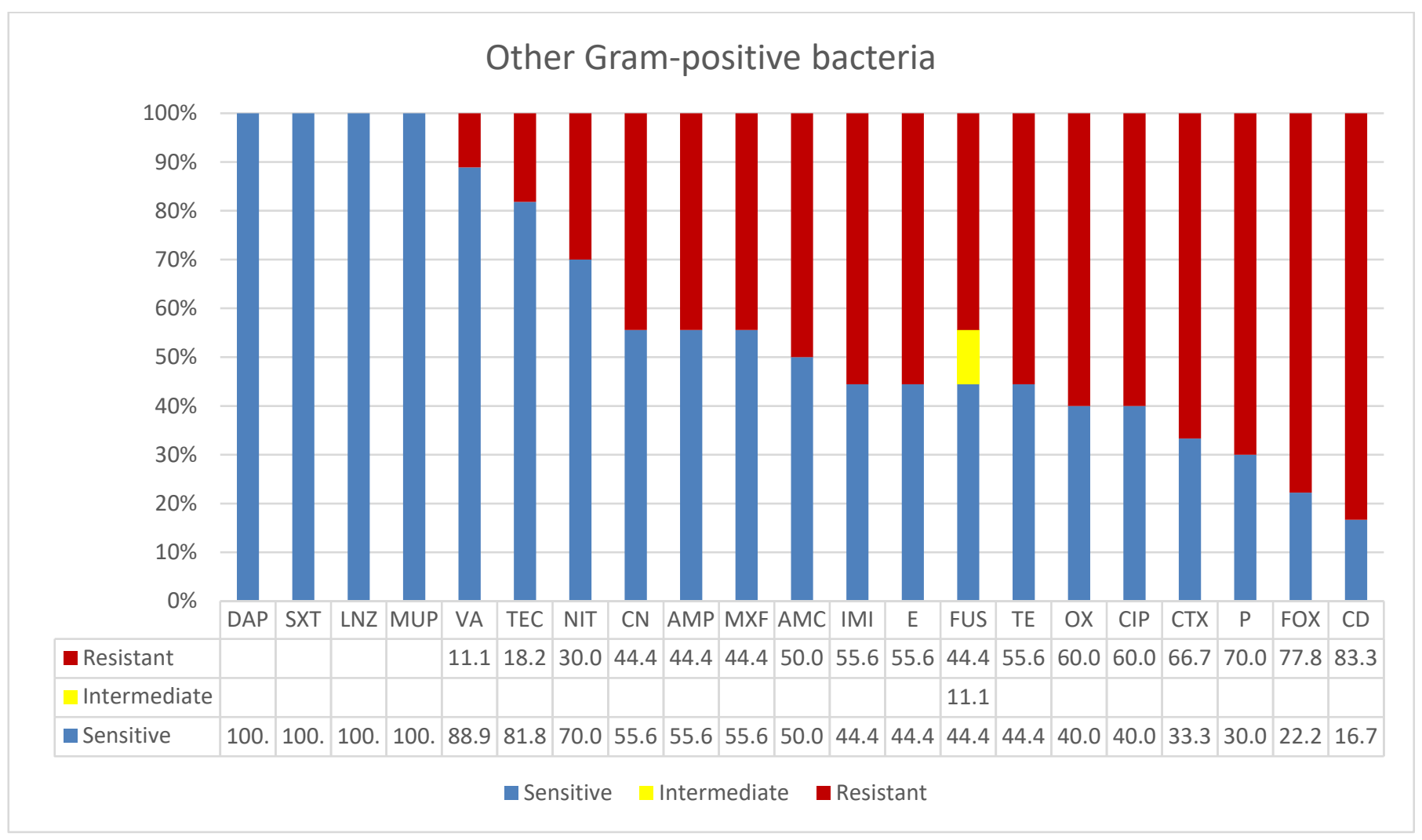

Figure 4. Antimicrobial sensitivity patterns of "Other Gram-positive bacteria" isolates to 21 antibiotics. Abbreviations (in the order in which they appear in the figure): DAP daptomycin, SXT trimethoprim*/sulfamethoxazole, LNZ linezolid, MUP mupirocin, VA vancomycin, TEC teicoplanin, NIT nitrofuran, CN gentamicin, AMP ampicillin, MXF moxifloxacin, AMC ampicillin*/sulbactam, IMI imipenem, E erythromycin, FUS fusidic acid, TE tetracycline, OX oxacillin, CIP ciprofloxacin, CTX cefotaxime, $P$ penicillin, FOX cefoxitin, CD clindamycin.

Thus, we have used combinations of molecular detection and influence of patient demographics on the frequency of infections and distributions of nosocomial Gram-positive bacteria among patients in different hospital units and wards. While most infections were bloodstream and surgical infections in the ICU and medical wards, being male and $\geq 50$ correlated well with frequency of infections; this will have significant implications in geriatric patient treatment and future management strategies. Future vertical studies 
on pan resistant VRE isolate, MRSA lineage types and gene contents, and S. epidermidis strain profiles would gain more insights. The overall reduced frequency of Gram-positives and their susceptibility to many antibiotics implied impressive success of patient nasal screening by automated molecular methods in the Ha'il region. The use of combinations of objective criteria is a robust and well thought out approach in infection control. However, the limitations of the study include short sampling time and its confinement to only major public hospitals; inclusion of all private hospitals and clinics, as well as neighboring cities would gain more insights and stricter control measures.

Supplementary Materials: The following are available online at https:/ / www.mdpi.com/article/ 10.3390/microbiolres13010004/s1. Table S1: Molecular characterization, specimen sources and type, patient demographics, and antibiogram patterns of clinical isolates of S. aureus and MRSA recovered from clinical specimens in major Ha'il Hospitals, against 22 antimicrobials. Table S2: Specimen sources and type, patient demographics and antibiogram patterns of S. epidermidis isolates, recovered from clinical specimens in major Ha'il Hospitals, against 21 antimicrobials. Table S3: Specimen sources and type, patient demographics and antibiogram patterns of E. faecalis isolates recovered from clinical specimens in major Ha'il Hospitals, against 21 antimicrobials. Table S4: Specimen sources and type, patient demographics and antibiogram patterns of "Other Gram positive bacteria" isolates, recovered from clinical specimens in major Ha'il Hospitals, against 21 antimicrobials.

Author Contributions: Conceptualization, K.B.S., Data curation, K.B.S., Ahmed Alsolami, A.M.K., N.A.K., S.M. (Soha Moursi), E.R., A.O., M.R., T.E.T., A.I.B., S.M. (Safia Moussa), A.A.J., H.N., M.K., O.M.A., A.S.A., A.A. (Abdulrahman Alfaraj), R.M.; Formal analysis K.B.S., A.A. (Ahmed Alsolami), A.M.K., N.A.K., S.M. (Soha Moursi), E.R., A.O., M.R., T.E.T., A.I.B., S.M. (Safia Moussa), A.A.J., H.N., M.K., O.M.A., A.S.A., A.A. (Abdulrahman Alfaraj), R.M.; Funding acquisition, K.B.S.; Investigation, K.B.S., A.A. (Ahmed Alsolami), A.M.K., E.R., T.E.T., S.M. (Safia Moussa), A.A.J., H.N., M.K., O.M.A., A.S.A., A.A. (Abdulrahman Alfaraj), R.M.; Methodology K.B.S., A.A. (Ahmed Alsolami), A.M.K., N.A.K., S.M. (Soha Moursi), E.R., A.O., M.R., T.E.T., A.I.B., S.M. (Safia Moussa), A.A.J., H.N., M.K., O.M.A., A.S.A., A.A. (Abdulrahman Alfaraj), R.M.; Project administration, K.B.S., A.S.A.; Resources, K.B.S., E.R., A.O., M.R., T.E.T., A.I.B., S.M. (Safia Moussa), A.A.J., H.N., O.M.A., A.A. (Abdulrahman Alfaraj), and R.M.; Software K.B.S., A.A. (Ahmed Alsolami), A.M.K., N.A.K., S.M. (Soha Moursi), E.R., A.O., M.R., T.E.T., A.I.B., A.A.J., M.K., O.M.A., A.S.A., A.A. (Abdulrahman Alfaraj), and R.M. Supervision, K.B.S., A.A. (Ahmed Alsolami), N.A.K., S.M. (Safia Moussa). Validation, K.B.S., A.A. (Ahmed Alsolami), A.M.K., N.A.K., S.M. (Soha Moursi), E.R., A.O., M.R., T.E.T., A.I.B., S.M. (Safia Moussa), A.A.J., H.N., M.K., O.M.A., A.S.A., A.A. (Abdulrahman Alfaraj), R.M. Visualization, K.B.S., A.A. (Ahmed Alsolami), A.M.K., N.A.K., S.M. (Soha Moursi), E.R., A.O., M.R., T.E.T., A.I.B., S.M. (Safia Moussa), A.A.J., H.N., M.K., O.M.A., A.S.A., A.A. (Abdulrahman Alfaraj), R.M. Writingoriginal draft, K.B.S.; Writing—review \& editing, K.B.S., A.A. (Ahmed Alsolami), A.M.K., N.A.K., S.M. (Soha Moursi), E.R., A.O., M.R., T.E.T., A.I.B., S.M. (Safia Moussa), A.A.J., H.N., M.K., O.M.A., A.S.A., A.A. (Abdulrahman Alfaraj), R.M. All authors have read and agreed to the published version of the manuscript.

Funding: This research has been funded by the Scientific Research Deanship at the University of Hail, Saudi Arabia through the project number RG191293.

Institutional Review Board Statement: This project (number 191293) has been approved by the Research Ethical Committee (H-2020-119, 175-42227) (REC at the University of Ha'il, dated 18/8/2020) and endorsed by the university president's letter number 55456/5/41, dated 29/12/2020, t44I H. In addition, the project has been reviewed and approved under the IRB registration number with KACST, Saudi Arabia: H-08-L-074, IRB log number: 2021-1/P.

Informed Consent Statement: Informed consent was obtained from all subjects involved in the study.

Data Availability Statement: There is no additional data deposited in any other site other than the Supplementary Material attached to this manuscript.

Acknowledgments: We acknowledge the University of Ha'l for support and encouragement through the Deanship of Scientific Research.

Conflicts of Interest: The authors declare no conflict of interest. 


\section{References}

1. Abussaud, M.J. Incidence of wound infection in three different departments and the antibiotic sensitivity pattern of the isolates in a Saudi Arabian hospital. Acta Microbiol. Et Immunol. Hung. 1996, 43, 301-305.

2. El-Mahdy, T.S.; Al-Agamy, M.H.; Emara, M.; Barakat, A.; Goering, R.V. Complex Clonal Diversity of Staphylococcus aureus Nasal Colonization among Community Personnel, Healthcare Workers, and Clinical Students in the Eastern Province, Saudi Arabia. BioMed Res. Int. 2018, 2018, 4208762. [CrossRef] [PubMed]

3. Rosenthal, V.D.; Belkebir, S.; Zand, F.; Afeef, M.; Tanzi, V.L.; Al-Abdely, H.M.; El-Kholy, A.; AlKhawaja, S.A.A.; Demiroz, A.P.; Sayed, A.F.; et al. Six-year multicenter study on short-term peripheral venous catheters-related bloodstream infection rates in 246 intensive units of 83 hospitals in 52 cities of 14 countries of Middle East: Bahrain, Egypt, Iran, Jordan, Kingdom of Saudi Arabia, Kuwait, Lebanon, Morocco, Pakistan, Palestine, Sudan, Tunisia, Turkey, and United Arab Emirates-International Nosocomial Infection Control Consortium (INICC) findings. J. Infect. Public Health 2020, 13, 1134-1141. [CrossRef] [PubMed]

4. Ghahremani, M.; Jazani, N.H.; Sharifi, Y. Emergence of vancomycin-intermediate and -resistant Staphylococcus aureus among methicillin-resistant S. aureus isolated from clinical specimens in the northwest of Iran. J. Global Antimicrob. Resist. 2018, 14, 4-9. [CrossRef] [PubMed]

5. $\quad$ Boswihi, S.S.; Udo, E.E.; Monecke, S.; Mathew, B.; Noronha, B.; Verghese, T.; Tappa, S.B. Emerging variants of methicillin-resistant Staphylococcus aureus genotypes in Kuwait hospitals. PLoS ONE 2018, 13, e0195933. [CrossRef] [PubMed]

6. Senok, A.; Ehricht, R.; Monecke, S.; Al-Saedan, R.; Somily, A. Molecular characterization of methicillin-resistant Staphylococcus aureus in nosocomial infections in a tertiary-care facility: Emergence of new clonal complexes in Saudi Arabia. New Microbes New Infect. 2016, 14, 13-18. [CrossRef]

7. Albarrag, A.; Shami, A.; Almutairi, A.; Alsudairi, S.; Aldakeel, S.; Al-Amodi, A. Prevalence and Molecular Genetics of MethicillinResistant Staphylococcus aureus Colonization in Nursing Homes in Saudi Arabia. Can. J. Infect. Dis. Med. Microbiol. 2020, 2020. [CrossRef]

8. $\quad$ El-Deeb, W.; Fayez, M.; Elmoslemany, A.; Kandeel, M.; Zidan, K. Methicillin resistant Staphylococcus aureus among goat farms in Eastern province, Saudi Arabia: Prevalence and risk factors. Prev. Vet. Med. 2018, 156, 84-90. [CrossRef]

9. Kourtis, A.P.; Hatfield, K.; Baggs, J.; Mu, Y.; See, I.; Epson, E.; Nadle, J.; Kainer, M.A.; Dumyati, G.; Petit, S.; et al. Vital Signs: Epidemiology and Recent Trends in Methicillin-Resistant and in Methicillin-Susceptible Staphylococcus aureus Bloodstream Infections-United States. MMWR Morb. Mortal. Wkly. Rep. 2019, 68, 214-219. [CrossRef]

10. Yilmaz, M.; Elaldi, N.; Balkan, I.I.; Arslan, F.; Batırel, A.A.; Bakı1ı, M.Z.; Gozel, M.G.; Alkan, S.; Çelik, A.D.; Yetkin, M.A. Mortality predictors of Staphylococcus aureus bacteremia: A prospective multicenter study. Ann. Clin. Microbiol. Antimicrob. 2016, 15, 7. [CrossRef]

11. Van Hal, S.J.; Jensen, S.O.; Vaska, V.L.; Espedido, B.A.; Paterson, D.L.; Gosbell, I.B. Predictors of mortality in Staphylococcus aureus Bacteremia. Clin. Microbiol. Rev. 2012, 25, 362-386. [CrossRef] [PubMed]

12. Rokney, A.; Baum, M.; Ben-Shimol, S.; Sagi, O.; Anuka, E.; Agmon, V.; Greenberg, D.; Valinsky, L.; Danino, D. Dissemination of the Methicillin-resistant Staphylococcus aureus Pediatric Clone (ST5-T002-IV-PVL+) as a Major Cause of Community-associated Staphylococcal Infections in Bedouin Children, Southern Israel. Pediatric Infect. Dis. J. 2019, 38, 230-235. [CrossRef] [PubMed]

13. Earls, M.R.; Steinig, E.J.; Monecke, S.; Castruita, J.A.S.; Simbeck, A.; Schneider-Brachert, W.; Vremeră, T.; Dorneanu, O.S.; Loncaric, I.; Bes, M.; et al. Exploring the evolution and epidemiology of European CC1-MRSA-IV: Tracking a multidrug-resistant community-associated meticillin-resistant Staphylococcus aureus clone. Microb. Genom. 2021, 7, 601. [CrossRef] [PubMed]

14. Gustave, C.A.; Tristan, A.; Martins-Simões, P.; Stegger, M.; Benito, Y.; Andersen, P.S.; Bes, M.; Le Hir, T.; Diep, B.A.; Uhlemann, A.C.; et al. Demographic fluctuation of community-acquired antibiotic-resistant Staphylococcus aureus lineages: Potential role of flimsy antibiotic exposure. ISME J. 2018, 12, 1879-1894. [CrossRef] [PubMed]

15. Cardot Martin, E.; Michel, A.; Raynal, B.; Badiou, C.; Laurent, F.; Vandenesch, F.; Etienne, J.; Lina, G.; Dumitrescu, O. Communityacquired meticillin-resistant Staphylococcus aureus strain USA300 resists staphylococcal protein A modulation by antibiotics and antimicrobial peptides. Int. J. Antimicrob. Agents 2015, 45, 19-24. [CrossRef]

16. Otto, M. Staphylococcus epidermidis-the "accidental" pathogen. Nat. Rev. Microbiol. 2009, 7, 555-567. [CrossRef]

17. Nguyen, T.H.; Park, M.D.; Otto, M. Host Response to Staphylococcus epidermidis Colonization and Infections. Front. Cell. Infect. Microbiol. 2017, 7, 90. [CrossRef]

18. De Leon, S.P.; Wenzel, R.P. Hospital-acquired bloodstream infections with Staphylococcus epidermidis. Review of 100 cases. Am. J. Med. 1984, 77, 639-644. [CrossRef]

19. Dong, Y.; Speer, C.P.; Glaser, K. Beyond sepsis: Staphylococcus epidermidis is an underestimated but significant contributor to neonatal morbidity. Virulence 2018, 9, 621-633. [CrossRef]

20. O'Toole, R.F. The interface between COVID-19 and bacterial healthcare-associated infections. Clinical microbiology and infection: The official publication of the European Society of Clinical Microbiology and Infectious Diseases. Clin. Microbiol. Infect. 2021, 27, 90. [CrossRef]

21. Dong, Y.; Speer, C.P. The role of Staphylococcus epidermidis in neonatal sepsis: Guarding angel or pathogenic devil? Int. J. Med. Microbiol. IJMM 2014, 304, 513-520. [CrossRef] [PubMed]

22. Cason, C.; D’accolti, M.; Campisciano, G.; Soffritti, I.; Ponis, G.; Mazzacane, S.; Maggiore, A.; Risso, F.M.; Comar, M.; Caselli, E. Microbial Contamination in Hospital Environment Has the Potential to Colonize Preterm Newborns' Nasal Cavities. Pathogens 2021, 10, 615. [CrossRef] 
23. Lee, J.Y.H.; Monk, I.R.; Gonçalves da Silva, A.; Seemann, T.; Chua, K.Y.; Kearns, A.; Hill, R.; Woodford, N.; Bartels, M.D.; Strommenger, B.; et al. Global spread of three multidrug-resistant lineages of Staphylococcus epidermidis. Nat. Microbiol. 2018, 3, 1175-1185. [CrossRef] [PubMed]

24. Rice, L.B. Federal funding for the study of antimicrobial resistance in nosocomial pathogens: No ESKAPE. J. Infect. Diseases 2008, 197, 1079-1081. [CrossRef] [PubMed]

25. Mulani, M.S.; Kamble, E.E.; Kumkar, S.N.; Tawre, M.S.; Pardesi, K.R. Emerging Strategies to Combat ESKAPE Pathogens in the Era of Antimicrobial Resistance: A Review. Front. Microbiol. 2019, 10, 539. [CrossRef] [PubMed]

26. Abat, C.; Raoult, D.; Rolain, J.M. Low Level of Resistance in Enterococci Isolated in Four Hospitals, Marseille, France. Microb. Drug Resist. 2016, 22, 218-222. [CrossRef]

27. Jernigan, J.A.; Hatfield, K.M.; Wolford, H.; Nelson, R.E.; Olubajo, B.; Reddy, S.C.; McCarthy, N.; Paul, P.; McDonald, L.C.; Kallen, A.; et al. Multidrug-Resistant Bacterial Infections in U.S. Hospitalized Patients, 2012-2017. N. Engl. J. Med. 2020, 382, 1309-1319. [CrossRef]

28. Zhou, Y.; Zhang, T. Trends in bacterial resistance among perioperative infections in patients with primary ovarian cancer: A retrospective 20-year study at an affiliated hospital in South China. J. Int. Med. Res. 2020, 48, 300060520928780. [CrossRef]

29. Khodabandeh, M.; Mohammadi, M.; Abdolsalehi, M.R.; Hasannejad-Bibalan, M.; Gholami, M.; Alvandimanesh, A.; Pournajaf, A.; Rajabnia, R. High-Level Aminoglycoside Resistance in Enterococcus Faecalis and Enterococcus Faecium; as a Serious Threat in Hospitals. Infect. Disord. Drug Targets 2020, 20, 223-228. [CrossRef]

30. Flokas, M.E.; Karageorgos, S.A.; Detsis, M.; Alevizakos, M.; Mylonakis, E. Vancomycin-resistant enterococci colonisation, risk factors and risk for infection among hospitalised paediatric patients: A systematic review and meta-analysis. Int. J. Antimicrob. Agents 2017, 49, 565-572. [CrossRef]

31. Herrera-Hidalgo, L.; de Alarcón, A.; López-Cortes, L.E.; Luque-Márquez, R.; López-Cortes, L.F.; Gutiérrez-Valencia, A.; GilNavarro, M.V. Enterococcus faecalis Endocarditis and Outpatient Treatment: A Systematic Review of Current Alternatives. Antibiotics 2020, 9, 657. [CrossRef] [PubMed]

32. Al-Ahdal, M.N.; Abozaid, S.M.; Al-Shammary, H.F.; Bohol, M.F.; Al-Thawadi, S.I.; Al-Jaberi, A.A.; Senok, A.C.; Shibl, A.M.; AlQahtani, A.A. Characterization of Enterococcus faecium isolates and first report of vanB phenotype-vanA genotype incongruence in the Middle East. Eur. J. Clin. Microbiol. Infect. Dis. 2012, 31, 3223-3229. [CrossRef] [PubMed]

33. Somily, A.M.; Al-Mohizea, M.M.; Absar, M.M.; Fatani, A.J.; Ridha, A.M.; Al-Ahdal, M.N.; Senok, A.C.; Al-Qahtani, A. Molecular epidemiology of vancomycin resistant enterococci in a tertiary care hospital in Saudi Arabia. Microb. Pathog. 2016, 97, 79-83. [CrossRef] [PubMed]

34. Abdallah, M.; Al-Saafin, M. Overview of Prevalence, Characteristics, Risk Factors, Resistance, and Virulence of VancomycinResistant Enterococci in Saudi Arabia. Microb. Drug Resist. 2019, 25, 350-358. [CrossRef] [PubMed]

35. Patel, J.B.; Cockerill, F.R.; Alder, J.; Bradford, P.A.; Dudley, M.N.; Eliopoulos, G.M.; Hardy, D.J.; Hecht, D.W.; Hindler, J.A.; Powell, M.; et al. Performance Standards for Antimicrobial Susceptibility Testing an Informational Supplement for Global Application Developed through the Clinical and Laboratory Standards Institute Consensus Process, 26th ed. Available online: www.clsi.org (accessed on 8 December 2021).

36. Magiorakos, A.P.; Srinivasan, A.; Carey, R.B.; Carmeli, Y.; Falagas, M.E.; Giske, C.G.; Harbarth, S.; Hindler, J.F.; Kahlmeter, G.; Olsson-Liljequist, B.; et al. Multidrug-resistant, extensively drug-resistant and pandrug-resistant bacteria: An international expert proposal for interim standard definitions for acquired resistance. Clin. Microbiol. Infect. Off. Publ. Eur. Soc. Clin. Microbiol. Infect. Dis. 2012, 18, 268-281. [CrossRef] [PubMed]

37. Zipperer, A.; Konnerth, M.C.; Laux, C.; Berscheid, A.; Janek, D.; Weidenmaier, C.; Burian, M.; Schilling, N.A.; Slavetinsky, C.; Marschal, M.; et al. Human commensals producing a novel antibiotic impair pathogen colonization. Nature 2016, 535, 511-516. [CrossRef] [PubMed]

38. Uslan, D.Z.; Crane, S.J.; Steckelberg, J.M.; Cockerill, F.R.; Sauver, J.L.S.; Wilson, W.R.; Baddour, L.M. Age- and sex-associated trends in bloodstream infection: A population-based study in Olmsted County, Minnesota. Arch. Intern. Med. 2007, 167, 834-839. [CrossRef] [PubMed]

39. Yahav, D.; Eliakim-Raz, N.; Leibovici, L.; Paul, M. Bloodstream infections in older patients. Virulence 2016, 7, 341-352. [CrossRef]

40. Bandy, A.; Almaeen, A.H. Pathogenic spectrum of blood stream infections and resistance pattern in Gram-negative bacteria from Aljouf region of Saudi Arabia. PLoS ONE 2020, 15, e0233704. [CrossRef]

41. Bouiller, K.; Ilic, D.; Wicky, P.H.; Cholley, P.; Chirouze, C.; Bertrand, X. Spread of clonal linezolid-resistant Staphylococcus epidermidis in an intensive care unit associated with linezolid exposure. Eur. J. Clin. Microbiol. Infect. Dis. Off. Publ. Eur. Soc. Clin. Microbiol. 2020, 39, 1271-1277. [CrossRef]

42. Weßels, C.; Strommenger, B.; Klare, I.; Bender, J.; Messler, S.; Mattner, F.; Krakau, M.; Werner, G.; Layer, F. Emergence and control of linezolid-resistant Staphylococcus epidermidis in an ICU of a German hospital. J. Antimicrob. Chemother. 2018, 73, 1185-1193. [CrossRef] [PubMed]

43. Xu, Z.; Cave, R.; Chen, L.; Yangkyi, T.; Liu, Y.; Li, K.; Meng, G.; Niu, K.; Zhang, W.; Tang, N.; et al. Antibiotic resistance and molecular characteristics of methicillin-resistant Staphylococcus epidermidis recovered from hospital personnel in China. J. Global Antimicrob. Resist. 2020, 22, 195-201. [CrossRef] [PubMed] 
44. Xu, Z.; Shah, H.N.; Misra, R.; Chen, J.; Zhang, W.; Liu, Y.; Cutler, R.R.; Mkrtchyan, H.V. The prevalence, antibiotic resistance and mecA characterization of coagulase negative staphylococci recovered from non-healthcare settings in London, UK. Antimicrob. Resist. Infect. Control 2018, 7, 73. [CrossRef] [PubMed]

45. Alghoribi, M.F.; Balkhy, H.H.; Woodford, N.; Ellington, M.J. The role of whole genome sequencing in monitoring antimicrobial resistance: A biosafety and public health priority in the Arabian Peninsula. J. Infect. Public Health 2018, 11, 784-787. [CrossRef]

46. Balkhi, B.; Mansy, W.; Alghadeer, S.; Alnuaim, A.; Alshehri, A.; Somily, A. Antimicrobial susceptibility of microorganisms causing Urinary Tract Infections in Saudi Arabia. J. Infect. Dev. Ctries. 2018, 12, 220-227. [CrossRef]

47. Kamińska, W.; Grochowska, M.; Chmielarczyk, A.; Olszewska, A.; Skolimowska, G.; Dzierżanowska-Fangrat, K. Genetic typing of Enterococcus faecium VRE strains isolated in three hospitals in Warsaw and Siedlce in 2015-2016. Przeglad Epidemiologiczny 2019, 73, 49-60. [CrossRef]

48. Conceição, N.; Rodrigues, W.F.; de Oliveira, K.L.P.; da Silva, L.E.P.; de Souza, L.R.C.; Barata, C.D.D.C.H.; de Oliveira, A.G. Beta-lactams susceptibility testing of penicillin-resistant, ampicillin-susceptible Enterococcus faecalis isolates: A comparative assessment of Etest and disk diffusion methods against broth dilution. Ann. Clin. Microbiol. Antimicrob. 2020, 19, 43. [CrossRef] [PubMed] 